\title{
Magnetic Field Perturbations to a Soft X-ray-Activated Fe (II) Molecular Spin State Transition
}

\author{
Guanhua Hao ${ }^{1,2}$, Alpha T. N’Diaye ${ }^{2, *}$, Thilini K. Ekanayaka ${ }^{1}$, Ashley S. Dale ${ }^{3} \mathbb{D}$, Xuanyuan Jiang ${ }^{1}$, \\ Esha Mishra ${ }^{1}$, Corbyn Mellinger ${ }^{1}{ }^{(D}$, Saeed Yazdani ${ }^{3}$, John W. Freeland ${ }^{4}$, Jian Zhang ${ }^{5}$, Ruihua Cheng ${ }^{3, *}$, \\ Xiaoshan $\mathrm{Xu}^{1}$ and Peter A. Dowben ${ }^{1, *(\mathbb{D})}$
}

check for

updates

Citation: Hao, G.; N’Diaye, A.T.; Ekanayaka, T.K.; Dale, A.S.; Jiang, X.; Mishra, E.; Mellinger, C.; Yazdani, S.; Freeland, J.W.; Zhang, J.; et al.

Magnetic Field Perturbations to a Soft X-ray-Activated Fe (II) Molecular Spin State Transition. Magnetochemistry 2021, 7, 135.

https://doi.org/10.3390/

magnetochemistry7100135

Academic Editor: Fabrice Pointillart

Received: 17 August 2021

Accepted: 15 September 2021

Published: 2 October 2021

Publisher's Note: MDPI stays neutral with regard to jurisdictional claims in published maps and institutional affiliations.

Copyright: (c) 2021 by the authors. Licensee MDPI, Basel, Switzerland. This article is an open access article distributed under the terms and conditions of the Creative Commons Attribution (CC BY) license (https:// creativecommons.org/licenses/by/ $4.0 /)$.
1 Department of Physics and Astronomy, University of Nebraska-Lincoln, Lincoln, NE 68588, USA; guanhuahao@huskers.unl.edu (G.H.); thiliniek@huskers.unl.edu (T.K.E.); neojxy@gmail.com (X.J.); emishra@huskers.unl.edu (E.M.); corbyn.mellinger@huskers.unl.edu (C.M.); xiaoshan.xu@unl.edu (X.X.)

2 Advanced Light Source, Lawrence Berkeley National Laboratory, Berkeley, CA 94720, USA

3 Physics Department, Indiana University Purdue University-Indianapolis, Indianapolis, IN 46202, USA; daleas@iupui.edu (A.S.D.); syazdani@iupui.edu (S.Y.)

4 Advanced Photon Source, Argonne National Laboratory, Argonne, IL 60439, USA; freeland@anl.gov

5 Molecular Foundry, Lawrence Berkeley National Laboratory, Berkeley, CA 94720, USA; JianZhang@lbl.gov

* Correspondence: atndiaye@lbl.gov (A.T.N.); rucheng@iupui.edu (R.C.); pdowben1@unl.edu (P.A.D.); Tel.: +1-510-486-5926 (A.T.N.); +1-317-274-6902 (R.C.); +1-402-472-9838 (P.A.D.)

\begin{abstract}
The X-ray-induced spin crossover transition of an Fe (II) molecular thin film in the presence and absence of a magnetic field has been investigated. The thermal activation energy barrier in the soft X-ray activation of the spin crossover transition for $\left[\mathrm{Fe}\left\{\mathrm{H}_{2} \mathrm{~B}(\mathrm{pz})_{2}\right\}_{2}\right.$ (bipy)] molecular thin films is reduced in the presence of an applied magnetic field, as measured through $X$-ray absorption spectroscopy at various temperatures. The influence of a $1.8 \mathrm{~T}$ magnetic field is sufficient to cause deviations from the expected exponential spin state transition behavior which is measured in the field free case. We find that orbital moment diminishes with increasing temperature, relative to the spin moment in the vicinity of room temperature.
\end{abstract}

Keywords: spin crossover; Fe (II) complex; activation barriers; X-ray excitation; magnetic field effects; $\left[\mathrm{Fe}\left\{\mathrm{H}_{2} \mathrm{~B}(\mathrm{pz})_{2}\right\}_{2}\right.$ (bipy)]; molecular multiferroic

\section{Introduction}

Switching of the spin state, and the accompanying conductivity, with an electric field is a long-sought goal with great potential for energy-efficient electronics and data storage. Such magneto-electric coupling has a long history [1], dating back to 1894 [2]. Currently, magneto-electric coupling is being explored in oxides, and raises increasing interest because magneto-electric and multiferroic materials are seen as a pathway to voltage-controlled nonvolatile logic [3,4] and memory [4]. There are few investigations of magneto-electric coupling in molecular systems, with clear demonstrations now provided for $\left[\mathrm{Mn}^{3+}(\mathrm{taa})\right]\left(\mathrm{H}_{3}\right.$ taa $=\operatorname{tris}(1-(2-a z o l y l)-2-a z a b u t e n-4-y l)$ amine $)[5,6]$, and $\left[\mathrm{Mn}^{3+}(3,5-\right.$ diBr-sal $\left.)_{2} 323\right) \mathrm{BPh}_{4}$ [7], which undergo a spin state transition; these have recently been accompanied by a complementary theory [7,8]. Magneto-electric coupling has also been observed in single crystals of $\mathrm{NiCl}_{2}-4 \mathrm{SC}\left(\mathrm{NH}_{2}\right)_{2}$ [9]. Magnetic fields have been seen to perturb the spin state transition in $\left[\mathrm{Mn}^{3+} \text { (taa)] [10], Fe(1,10-phenanthroline }\right)_{2}(\mathrm{NCS})_{2}$ [9], $\mathrm{Fe}(\mathrm{phen})_{2}(\mathrm{NCS})_{2}[11],\left[\mathrm{Fe}\left\{\mathrm{H}_{2} \mathrm{~B}(\mathrm{pz})_{2}\right\}_{2}\right.$ (bipy)] $\left(\mathrm{H}_{2} \mathrm{~B}(\mathrm{pz})_{2}=\right.$ bis(hydrido)bis $(1 H$-pyrazol-1-yl) borate, bipy $=2,2^{\prime}$-bipyridine) [12]. These latter spin crossover systems all have a static electric dipole which is intrinsically dependent on the spin state; therefore, the perturbation of the spin state, such as with a magnetic field, is an example of magneto-electric coupling because there is an accompanying change in the electric polarization.

The fact that the application of a magnetic field tends to relax $\left[\mathrm{Fe}\left\{\mathrm{H}_{2} \mathrm{~B}(\mathrm{pz})_{2}\right\}_{2}(\mathrm{bipy})\right]$ back to the low-spin state after the soft X-ray excitation to the high-spin state [12] suggests 
that an applied magnetic field may lower the activation barriers separating high-spin and low-spin states. A lowering of the free energy of the high-spin state and a decrease in the activation barrier separating the high-spin state from the low-spin state, by application of a magnetic field, has also been suggested for $\mathrm{Fe}(\mathrm{phen})_{2}(\mathrm{NCS})_{2}$ [11]. This magneticfield-induced perturbation of the low-spin to high-spin state barrier is explored here for $\left[\mathrm{Fe}\left\{\mathrm{H}_{2} \mathrm{~B}(\mathrm{pz})_{2}\right\}_{2}\right.$ (bipy)]. The influence of magnetic fields on the excitation and de-excitation in molecules has been observed before [13-18] and is not unique to spin crossover complexes. These latter studies are not of molecular systems, but organics such as anthracene and rubrene where this phenomenon arises due to the coupling of a molecule in the electronic singlet ground state with an adjacent molecule in the first excited singlet state to form a correlated triplet-pair state. In the case of $\left[\mathrm{Fe}\left\{\mathrm{H}_{2} \mathrm{~B}(\mathrm{pz})_{2}\right\}_{2}(\mathrm{bipy})\right]$, the excitation is accompanied by a spin state change $[12,19]$ and can be influenced by an applied magnetic field. Looking forward, understanding perturbations to the spin state transition, caused by a magnetic field, is a step toward elucidating the origin of any magneto-electric coupling.

\section{Results}

\subsection{Magnetic Field Effects on the Excitation of a Spin Crossover Molecule}

As previously reported [12], soft X-ray irradiation excites $\left[\mathrm{Fe}\left\{\mathrm{H}_{2} \mathrm{~B}(\mathrm{pz})_{2}\right\}_{2}\right.$ (bipy)] thin films on $\mathrm{NiCO}_{2} \mathrm{O}_{4}(111)$ from the low-spin state to the high-spin state. Furthermore, an alternating magnetic field has been shown to perturb the $\left[\mathrm{Fe}\left\{\mathrm{H}_{2} \mathrm{~B}(\mathrm{pz})_{2}\right\}_{2}\right.$ (bipy)] thin film spin state on $\mathrm{NiCo}_{2} \mathrm{O}_{4}(111)$ [12]. Here, we demonstrate how a static applied magnetic field subtly changes the characteristics of the spin state evolution induced by incident $X$-rays.

The spin state occupancy of $\left[\mathrm{Fe}\left\{\mathrm{H}_{2} \mathrm{~B}(\mathrm{pz})_{2}\right\}_{2}\right.$ (bipy)] $\mathrm{Fe}(\mathrm{II})$ thin films may be ascertained from the X-ray absorption spectra (XAS) [12,19-27]. In the low-spin (LS) state of the $\left[\mathrm{Fe}\left\{\mathrm{H}_{2} \mathrm{~B}(\mathrm{pz})_{2}\right\}_{2}\right.$ (bipy)] molecule, the $3 d$ electrons occupy the $t_{2 \mathrm{~g}}$ orbitals in pairs, leaving the $\mathrm{e}_{\mathrm{g}}$ orbitals empty. The empty $\mathrm{e}_{\mathrm{g}}$ orbitals are generally observed in the Fe $\mathrm{L}_{3}$ edge $\left(2 \mathrm{p}_{3 / 2}\right)$ X-ray absorption spectra as a major feature at a photon energy around $708.9 \mathrm{eV}$. In the high-spin (HS) state configuration, the $e_{g}$ orbitals are partially populated while the $t_{2 g}$ orbitals become partly depopulated, which thus contributes features in the XAS spectra at lower photon energies, leading to a decrease in the peak intensity at $708.9 \mathrm{eV}$ and an increase in the $t_{2 g}$ shoulder at around $706.8 \mathrm{eV}$, as shown in Figure 1. The asymmetry between the empty $t_{2 g}$ and empty $e_{g}$ state peaks is a measure of the fraction of molecules in the high-spin state, as has been shown experimentally [12,19-27]. Such analysis of the XAS spectra is also in agreement with the theory as the spin state occupancy changes [20].
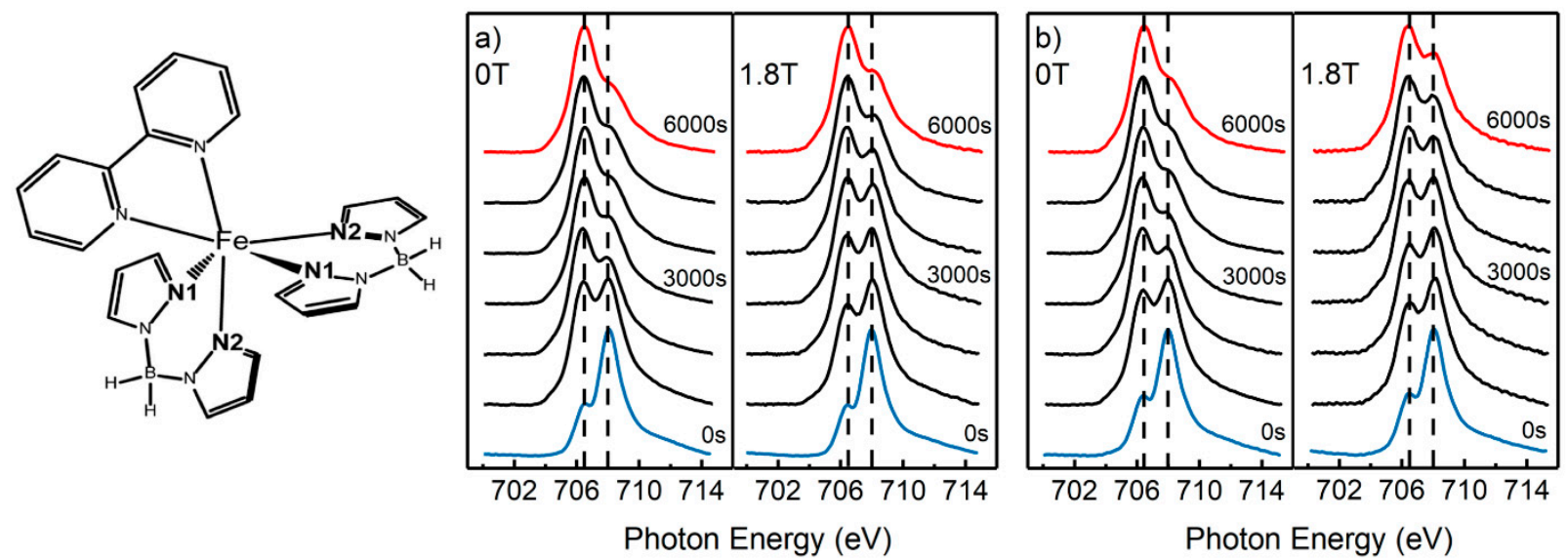

Figure 1. The time evolution of the X-ray absorption spectra of $\left[\mathrm{Fe}\left\{\mathrm{H}_{2} \mathrm{~B}(\mathrm{pz})_{2}\right\}_{2}\right.$ (bipy)] thin films, on $\mathrm{NiCo}_{2} \mathrm{O}_{4}(111)$, with and without an applied 1.8 T magnetic field, under a constant incident X-ray fluence at (a) $300 \mathrm{~K}$ and (b) $200 \mathrm{~K}$. The spectra in blue are indicative of a film in a largely low-spin state (roughly $30 \%$ high-spin), whereas the spectra in red are largely indicative of a high-spin state. On the left is a schematic of $\left[\mathrm{Fe}\left\{\mathrm{H}_{2} \mathrm{~B}(\mathrm{pz})_{2}\right\}_{2}\right.$ (bipy)] $\left(\mathrm{H}_{2} \mathrm{~B}(\mathrm{pz})_{2}=\right.$ bis(hydrido)bis(1H-pyrazol-1-yl) borate, bipy $=2,2^{\prime}$-bipyridine). Hydrogens are omitted for clarity. 
There is an evolution of the XAS spectra of $\left[\mathrm{Fe}\left\{\mathrm{H}_{2} \mathrm{~B}(\mathrm{pz})_{2}\right\}_{2}(\mathrm{bipy})\right]$ thin films, on $\mathrm{NiCO}_{2} \mathrm{O}_{4}(111)$, that occurs with an incident X-ray fluence, as seen in Figure 1. From these spectra, there is clear evidence of an evolution of the average spin state from a lowspin state towards a larger fraction of high-spin state occupancy with increasing incident X-ray fluence, as reported elsewhere [12]. This soft X-ray excitation into the high-spin state has been demonstrated to be reversible [12].

This evolution of the average spin state occupancy is perturbed by the presence of an external magnetic field. The XAS spectra indicate differences in the spin state occupancy for identical X-ray exposures where the only variable is the applied external magnetic field. Figure 1a shows spectra from the time evolution at $300 \mathrm{~K}$, measured both without any magnetic field and with an applied field of $1.8 \mathrm{~T}$. The $\mathrm{e}_{\mathrm{g}}$ to $\mathrm{t}_{2 \mathrm{~g}}$ peak ratios for the initial state are identical, whereas the XAS spectra, with and without an applied magnetic field, differ markedly after $3000 \mathrm{~s}$ of X-ray exposure. Analyses of the relative intensities of the $e_{g}$ and $t_{2 g}$ XAS features show that in the absence of an applied magnetic field, the $\left[\mathrm{Fe}\left\{\mathrm{H}_{2} \mathrm{~B}(\mathrm{pz})_{2}\right\}_{2}\right.$ (bipy)] molecular thin film achieves a more than $80 \%$ occupancy in the highspin state after $3000 \mathrm{~s}$ of $\mathrm{X}$-ray exposure. In the presence of a $1.8 \mathrm{~T}$ out-of-plane applied magnetic field, however, the $\left[\mathrm{Fe}\left\{\mathrm{H}_{2} \mathrm{~B}(\mathrm{pz})_{2}\right\}_{2}\right.$ (bipy)] molecular thin film resides in a mixed spin state with a smaller high-spin state fraction (i.e., $<70 \%$ high-spin), as summarized in Figure 2. Differences in the spin state occupancy are evident at $200 \mathrm{~K}, 250 \mathrm{~K}$ and $300 \mathrm{~K}$ temperatures as well (Figure $1 \mathrm{~b}$ and Supplementary Material). This is consistent with prior observations that the magnetic field has been seen to perturb the $\left[\mathrm{Fe}\left\{\mathrm{H}_{2} \mathrm{~B}(\mathrm{pz})_{2}\right\}_{2}\right.$ (bipy)] thin film spin state on $\mathrm{NiCo}_{2} \mathrm{O}_{4}(111)$ [12].
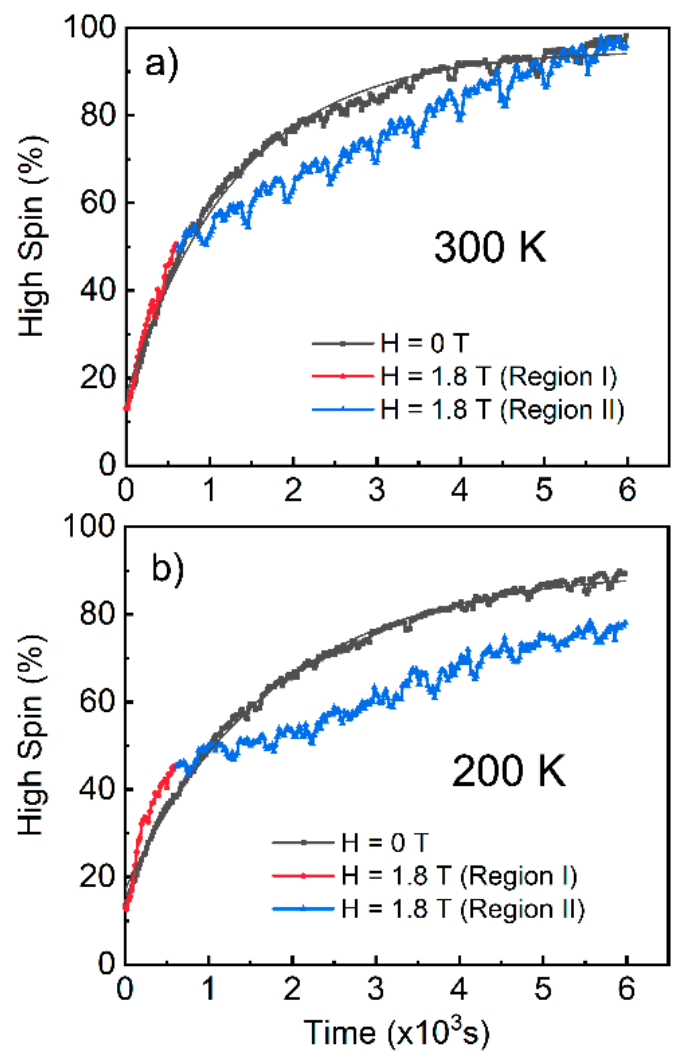

Figure 2. The evolution of the high-spin state occupancy in the $\left[\mathrm{Fe}\left\{\mathrm{H}_{2} \mathrm{~B}(\mathrm{pz})_{2}\right\}_{2}\right.$ (bipy)] thin films, on $\mathrm{NiCO}_{2} \mathrm{O}_{4}(111)$, that accompany an incident soft $\mathrm{X}$-ray fluence are plotted for (a) $300 \mathrm{~K}$ and (b) $200 \mathrm{~K}$, in the absence of an applied magnetic field (black) as well as in the presence of a 1.8 T applied magnetic field (red and blue). Exponential fits to the high-spin state conversion in the absence of an applied magnetic field are indicated. 
To clarify this soft X-ray-induced spin state evolution of $\left[\mathrm{Fe}\left\{\mathrm{H}_{2} \mathrm{~B}(\mathrm{pz})_{2}\right\}_{2}\right.$ (bipy)] molecular thin film on $\mathrm{NiCO}_{2} \mathrm{O}_{4}(111)$, with and without an applied magnetic field, we extracted the occupancy evolution from series of spectra taken over the course of $6000 \mathrm{~s}$ (the data for $200 \mathrm{~K}$ and $300 \mathrm{~K}$ are plotted in Figure 2). All temperatures shown here are above the spin crossover temperature of the pure molecule, which is generally observed to occur at about $160 \mathrm{~K}[20-22,26,28-30]$. However, without an incident X-ray fluence, the $\left[\mathrm{Fe}\left\{\mathrm{H}_{2} \mathrm{~B}(\mathrm{pz})_{2}\right\}_{2}\right.$ (bipy)] molecular thin films on $\mathrm{NiCo}_{2} \mathrm{O}_{4}$ (111) are locked in the low-spin state by the interface to the substrate [12]. The evolution towards the high-spin state is the result of the X-ray fluence overcoming the tendency of the substrate to lock the $\left[\mathrm{Fe}\left\{\mathrm{H}_{2} \mathrm{~B}(\mathrm{pz})_{2}\right\}_{2}\right.$ (bipy)] molecular thin film in the low-spin state. In the presence of an applied magnetic field, the initial increase towards the high-spin state occupancy is rapid (red shaded curves in Figure 2). We denote this initial increase in high-spin state occupancy as region I. This is followed by a slower and more linear increase in high-spin state occupancy (the blue shaded curves in Figure 2). We denote this latter evolution toward the high-spin state, in an applied magnetic field, as region II. This evolution towards high-spin state occupancy behavior, in an applied magnetic field, differs significantly from the exponential increase in high-spin state occupancy observed in the absence of an applied magnetic field (black shaded curves in Figure 2).

The excitation to the high-spin state in the presence of the X-ray fluence and an applied magnetic field is complicated by competing processes, which are also evident from the fluctuations in the evolution to the high-spin state (Figure 2, blue regions). These fluctuations, on the time scale of $10 \mathrm{~s}$ to $200 \mathrm{~s}$ in region II (Figure 2, blue regions), are both magnetic field and temperature dependent, and are thus unlikely to be instrumental, but are indicative of competing dynamic processes whose nature should be investigated but is outside the scope of this work. Here, we focus on the effects on a long timescale of tens of minutes to hours.

\subsection{The Temperature Dependence of the Spin-to-Orbital Moment Ratio}

A thermal component to the magnetic moment and the spin state transition most likely occurs through the ligands. This implies that the orbital moment is more susceptible to temperature than the spin moment in the high-spin state. To test this, we measured the spin and orbital moments of $\left[\mathrm{Fe}\left\{\mathrm{H}_{2} \mathrm{~B}(\mathrm{pz})_{2}\right\}_{2}\right.$ (bipy) $]$ thin films in the high-spin state on a substrate where the influence of the substrate on the spin state of the $\left[\mathrm{Fe}\left\{\mathrm{H}_{2} \mathrm{~B}(\mathrm{pz})_{2}\right\}_{2}\right.$ (bipy)] thin film is known to be minimal, e.g., graphite $[25,26]$. Temperatures in the vicinity of $300 \mathrm{~K}$ are well above the spin state transition of about $160 \mathrm{~K}[20-22,26,28-30]$ as noted above, but thermal effects are seen in the orbital contribution to the local moments, as seen in X-ray circular dichroism (XMCD) spectra at the Fe $2 p$ core thresholds of $\left[\mathrm{Fe}\left\{\mathrm{H}_{2} \mathrm{~B}(\mathrm{pz})_{2}\right\}_{2}(\right.$ bipy) $]$ thin films on graphite in Figure 3.

The normalized XMCD data, for the $\mathrm{Fe} 2 \mathrm{p}_{3 / 2}$ and $2 \mathrm{p}_{1 / 2}$ ( $\mathrm{L}_{3}$ and $\mathrm{L}_{2}$ edges) of $\left[\mathrm{Fe}\left\{\mathrm{H}_{2} \mathrm{~B}(\mathrm{pz})_{2}\right\}_{2}\right.$ (bipy)] thin films on graphite, are shown in Figure $3 \mathrm{a}$ for different temperatures. After subtracting a linear background, sum rules were applied to calculate the average spin moment based on the relative integrated XMCD signals, as shown in Figure $3 b$, following the procedure of Chen et al. [31]. The moments obtained from XMCD will be only a small fraction of the actual $\mathrm{Fe}$ (II) moments, largely because the $\left[\mathrm{Fe}\left\{\mathrm{H}_{2} \mathrm{~B}(\mathrm{pz})_{2}\right\}_{2}\right.$ (bipy)] moments are not saturated [32]. Contributing to the low moment measured, it should be noted that the incident light is elliptical, not perfectly circularly polarized, and there is likely a misalignment of light angular momentum vector with respect to the magnetic moment, in addition to the Fresnel boundary conditions in play. However, in the highspin state, $\left[\mathrm{Fe}\left\{\mathrm{H}_{2} \mathrm{~B}(\mathrm{pz})_{2}\right\}_{2}\right.$ (bipy)] represents a molecular local moment system. As seen in Figure $4 a$, the relative spin moment $S_{z}($ red), extracted from the $X M C D$ spectra, is relatively insensitive to small changes in temperature, whereas the relative orbital moment $\mathrm{L}_{\mathrm{z}}$ (blue) decreases significantly with a small increase in temperature for the $\left[\mathrm{Fe}\left\{\mathrm{H}_{2} \mathrm{~B}(\mathrm{pz})_{2}\right\}_{2}\right.$ (bipy)] on graphite sample. 

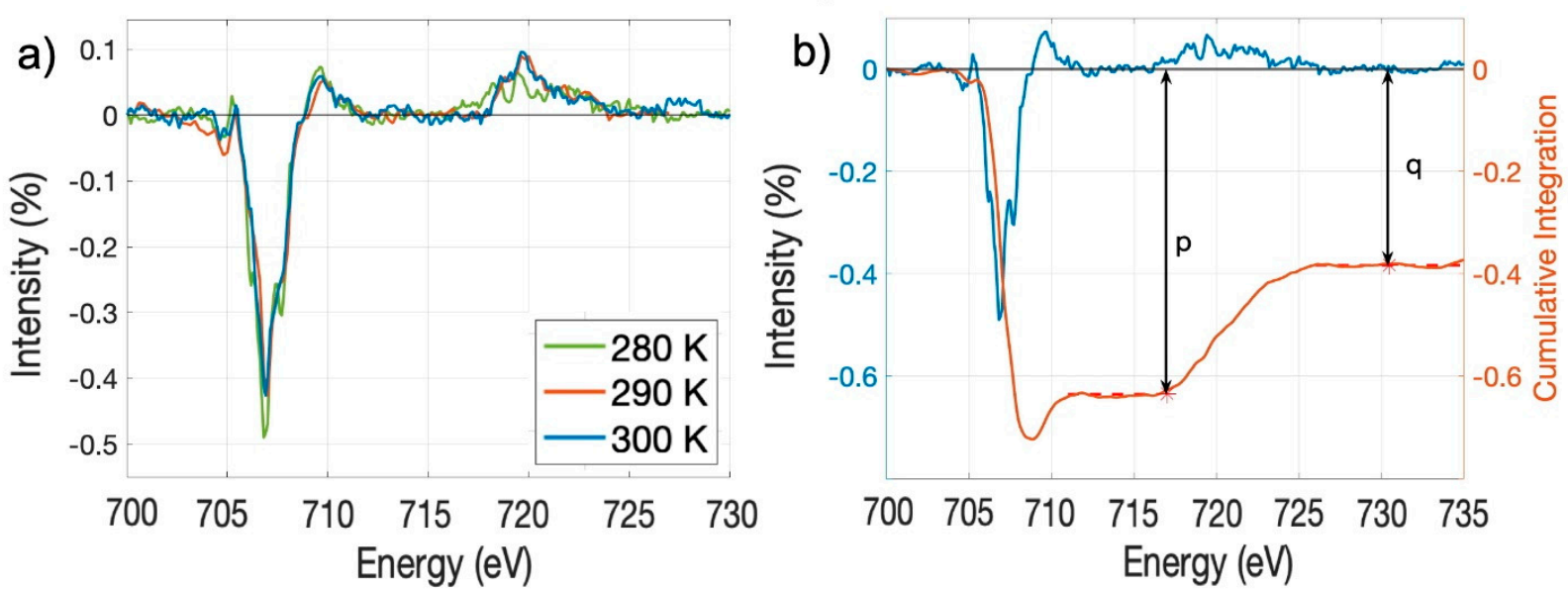

Figure 3. The Fe $2 \mathrm{p}_{3 / 2}$ and $2 \mathrm{p}_{1 / 2}\left(\mathrm{~L}_{3}\right.$ and $\mathrm{L}_{2}$ edges) XMCD spectra of $30 \mathrm{~nm}\left[\mathrm{Fe}\left\{\mathrm{H}_{2} \mathrm{~B}(\mathrm{pz})_{2}\right\}_{2}(\mathrm{bipy})\right]$ thin films on graphite. (a) The spectra were taken at $280 \mathrm{~K}$ (green), $290 \mathrm{~K}$ (red) and $300 \mathrm{~K}$ (blue). (b) The Fe $2 \mathrm{p}_{3 / 2}$ and $2 \mathrm{p}_{1 / 2}\left(\mathrm{~L}_{3}\right.$ and $\left.\mathrm{L}_{2}\right) \mathrm{XMCD}$ spectrum taken at $280 \mathrm{~K}$ (blue curve) compared to the integrated XMCD signal (red curve). The XMCD spectra are plotted as a percentage of the total $\mathrm{X}$-ray absorption spectra.
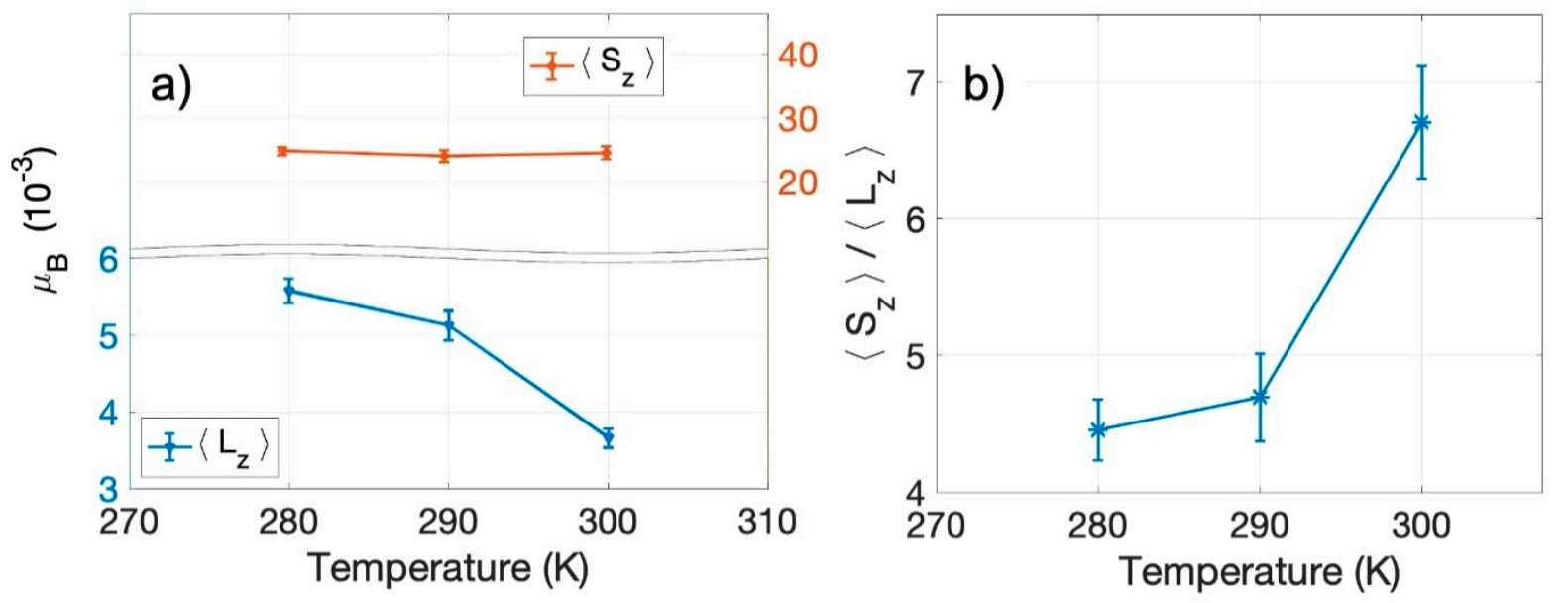

Figure 4. The temperature dependence of the relative spin $\mathrm{S}_{\mathrm{Z}}$ and orbital $\mathrm{L}_{\mathrm{z}}$ moments extracted from Fe (II) XMCD taken from a $30 \mathrm{~nm}\left[\mathrm{Fe}\left\{\mathrm{H}_{2} \mathrm{~B}(\mathrm{pz})_{2}\right\}_{2}\right.$ (bipy)] thin film on graphite. (a) The temperature-dependent spin moment (red plot) and orbital moment (blue plot) of Fe (II). (b) The ratio of spin moment $\mathrm{S}_{\mathrm{z}}$ to orbital moment $\mathrm{L}_{\mathrm{z}}$ as a function of temperature in the vicinity of room temperature.

The expected spin-to-orbital moment ratio should lie between three and six for an $\mathrm{Fe}$ (II) spin crossover complex, such as $\left[\mathrm{Fe}\left\{\mathrm{H}_{2} \mathrm{~B}(\mathrm{pz})_{2}\right\}_{2}\right.$ (bipy)], in the high-spin state [33]. Estimating the ratio of the spin to orbital moment from the XMCD spectra as $\left\langle\mathrm{S}_{\mathrm{z}}\right\rangle /\left\langle\mathrm{L}_{\mathrm{z}}\right\rangle=$ $(9 p-6 q) / 2 q[31]$, with $p$ and $q$ determined from the integrated XMCD plots, as indicated in Figure 3, we found that the $\left\langle\mathrm{S}_{\mathrm{z}}>/<\mathrm{L}_{\mathrm{z}}>\right.$ was from about 4.5 to nearly 7 (Figure $4 \mathrm{~b}$ ). This is reasonably consistent with expectations. More surprising is that the spin-to-orbital moment ratio $\left\langle\mathrm{S}_{\mathrm{z}}\right\rangle /\left\langle\mathrm{L}_{\mathrm{z}}\right\rangle$ varied widely with small changes in temperature (Figure $4 \mathrm{~b}$ ) as a result of the changes in orbital moment with temperature (Figure 4a). This indicates that the orbital moment of $\left[\mathrm{Fe}\left\{\mathrm{H}_{2} \mathrm{~B}(\mathrm{pz})_{2}\right\}_{2}\right.$ (bipy)] is very soft with respect to temperature changes.

\section{Discussion}

It is clear that a static applied magnetic field has an influence on the $\mathrm{X}$-ray-induced transition from the low-spin to high-spin state for $\left[\mathrm{Fe}\left\{\mathrm{H}_{2} \mathrm{~B}(\mathrm{pz})_{2}\right\}_{2}\right.$ (bipy)] molecular thin films on $\mathrm{NiCo}_{2} \mathrm{O}_{4}(111)$. We note that, in the absence of an applied magnetic field, the observed exponential increase in high-spin state occupancy for $\left[\mathrm{Fe}\left\{\mathrm{H}_{2} \mathrm{~B}(\mathrm{pz})_{2}\right\}_{2}(\right.$ bipy $\left.)\right]$ molecular thin films 
on $\mathrm{NiCo}_{2} \mathrm{O}_{4}(111)$, between $200 \mathrm{~K}$ and $300 \mathrm{~K}$ (black shaded curves in Figure 2), resembles the exponential increase in high-spin state occupancy observed as a result of X-ray beam induce low-spin state (LS) to high-spin state (HS) transitions at low temperatures (5 K), seen for $\left[\mathrm{Fe}\left\{\mathrm{H}_{2} \mathrm{~B}(\mathrm{pz})_{2}\right\}_{2}\right.$ (bipy)] molecular thin films on graphite $[25,26]$. This soft $X$-ray-induced excited spin state trapping (SOXIESST), seen for $\left[\mathrm{Fe}\left\{\mathrm{H}_{2} \mathrm{~B}(\mathrm{pz})_{2}\right\}_{2}\right.$ (bipy)] molecular thin films on graphite at below $40-50 \mathrm{~K}$, occurs because the graphite substrate does not lock the spin state of the $\left[\mathrm{Fe}\left\{\mathrm{H}_{2} \mathrm{~B}(\mathrm{pz})_{2}\right\}_{2}\right.$ (bipy)] molecular thin films into the low-spin state $[25,26]$. In contrast to the case of graphite where the graphite substrate is the weakly interacting $\{25,26]$, a spin state locking effect occurs for $\left[\mathrm{Fe}\left\{\mathrm{H}_{2} \mathrm{~B}(\mathrm{pz})_{2}\right\}_{2}\right.$ (bipy)] molecular thin films on $\mathrm{NiCO}_{2} \mathrm{O}_{4}(111)$ [12].

The temperature dependence of the spin state evolution provides an opportunity to estimate the thermal component of the activation barrier in this X-ray-induced transition. Arrhenius rate plots with temperature (Figure 5) were calculated based on the high-spin occupancy results shown above, based on the initial rates of spin state. In the absence of an applied magnetic field, an activation barrier of $14.5 \pm 1.5 \mathrm{meV}$ per molecule was calculated. The initial rates of $\left[\mathrm{Fe}\left\{\mathrm{H}_{2} \mathrm{~B}(\mathrm{pz})_{2}\right\}_{2}\right.$ (bipy)] conversion to the high-spin state in an applied magnetic field (region I, in Figure 2) suggest a somewhat lower activation energy of 7.2 \pm $2 \mathrm{meV}$, as schematically illustrated in Figure 6. After a significant fraction of the film has already been converted to the high-spin state (region II in Figure 2), the activation energy in an applied magnetic field is again restored to $15.9 \pm 2.7 \mathrm{meV}$, as indicated by the inset in Figure 5. A magnetic field dependence on the free energy and activation barrier has been suggested for the Fe (phen $)_{2}(\mathrm{NCS})_{2}$ spin state transition [11]; thus, the effect of larger magnetic fields than those exploited here is of considerable interest.

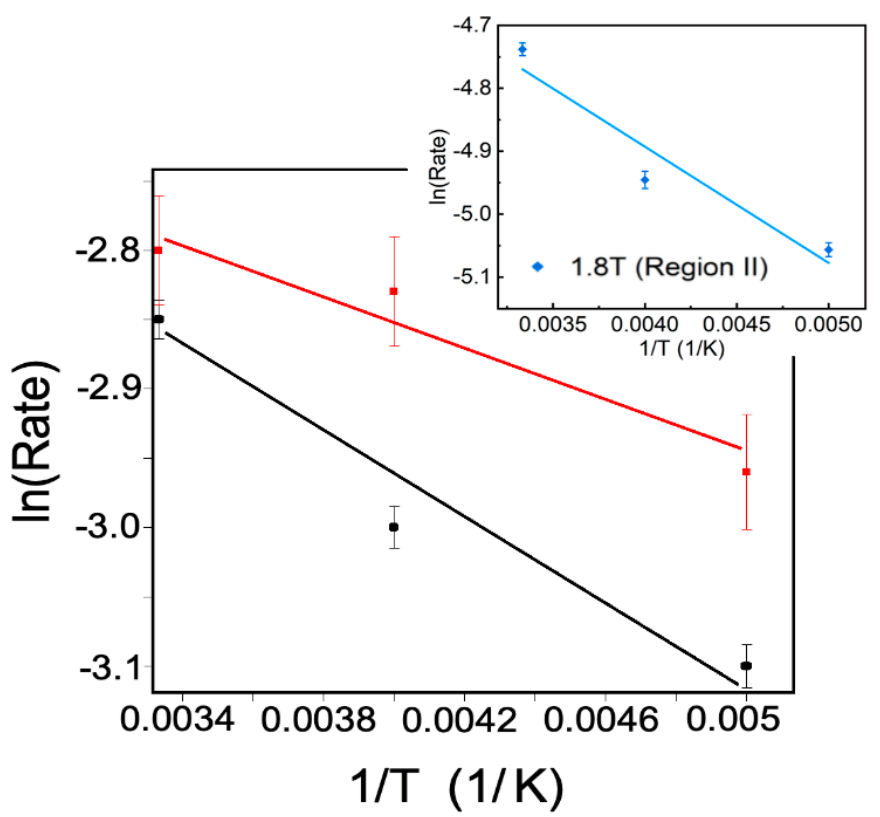

Figure 5. The temperature-dependent Arrhenius plots of the conversion rate to a high-spin state for $\left[\mathrm{Fe}\left\{\mathrm{H}_{2} \mathrm{~B}(\mathrm{pz})_{2}\right\}_{2}\right.$ (bipy)] thin films on $\mathrm{NiCo}_{2} \mathrm{O}_{4}(111)$, induced by a soft $\mathrm{X}$-ray fluence. In the absence of an applied magnetic field, this temperature dependence indicates a thermal component of the activation energy of $14.5 \pm 1.5 \mathrm{meV}$ (black). The Arrhenius plot for the initial period when $1.8 \mathrm{~T}$ external magnetic field is applied (region I, Figure 2) suggests a thermal component of the activation energy of $7.2 \pm 2 \mathrm{meV}$ (red). The inset is the Arrhenius plot for the following $1.8 \mathrm{~T}$ transition to the high-spin state when a significant fraction of the $\left[\mathrm{Fe}\left\{\mathrm{H}_{2} \mathrm{~B}(\mathrm{pz})_{2}\right\}_{2}\right.$ (bipy)] thin film on $\mathrm{NiCo}_{2} \mathrm{O}_{4}(111)$ has converted to the high-spin state (region II, Figure 2) and indicates a thermal component of the activation energy of $15.9 \pm 2.7 \mathrm{meV}$ (blue). 


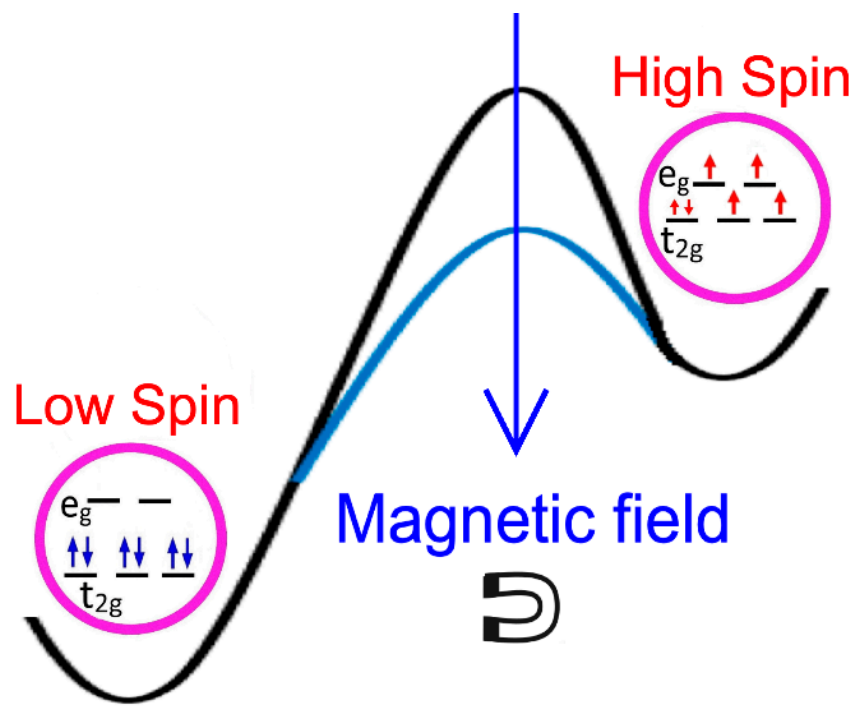

Figure 6. A schematic representation of the reduction in the thermal activation barrier in the presence of a magnetic field.

The decrease in the thermal component to the activation energy can also explain the conversion rate curves of Figure 2 for this $X$-ray-induced transition. When the $\left[\mathrm{Fe}\left\{\mathrm{H}_{2} \mathrm{~B}(\mathrm{pz})_{2}\right\}_{2}(\mathrm{bipy})\right]$ high-spin state occupancy increases enough, it is clear that X-ray-induced photo-excitation to the high-spin state of the small amount of material remaining in the low-spin state begins to compete with the conversion of the large amount of film in the high-spin state back to the low-spin state favored by the $\left[\mathrm{Fe}\left\{\mathrm{H}_{2} \mathrm{~B}(\mathrm{pz})_{2}\right\}_{2}(\right.$ bipy) $]$ interaction with the $\mathrm{NiCo}_{2} \mathrm{O}_{4}$ (111) substrate. This is certainly consistent with a nearly $50 \%$ decline in activation energy with the application of a magnetic field. Due to possible inhomogeneities, such as a distribution of crystalline grain sizes, the thermal energy barriers towards conversion to the high-spin state or back-conversion to the low-spin state could only be lowered for part of the film, either unchanged or retaining a different value for another part of the film.

The presence of this low-spin state back-conversion prevents a full excitation into the high-spin state when there is an applied magnetic field. Indeed, this enhanced backconversion to the low-spin state has previously been seen for $\left[\mathrm{Fe}\left\{\mathrm{H}_{2} \mathrm{~B}(\mathrm{pz})_{2}\right\}_{2}\right.$ (bipy)] thin films, as a result of the applied alternating magnetic field [12]. It is the competition between excitation to the high-spin state and the enhanced back conversion to the low-spin state which then leads to the apparent increase in the thermal component of the activation energy. The appearance of two regimes in the soft X-ray-fluence-induced evolution (regions I and II in Figure 2) can be explained by expanding the model to include two separate conversion rates, as indicated in models of the spin crossover plotted in Figure 7. This difference in $\left[\mathrm{Fe}\left\{\mathrm{H}_{2} \mathrm{~B}(\mathrm{pz})_{2}\right\}_{2}\right.$ (bipy)] spin state conversion rates could either be induced by heterogeneity or by a different behavior of the film depending on the proximity to the substrate or vacuum interface, as has been observed before [21]. 


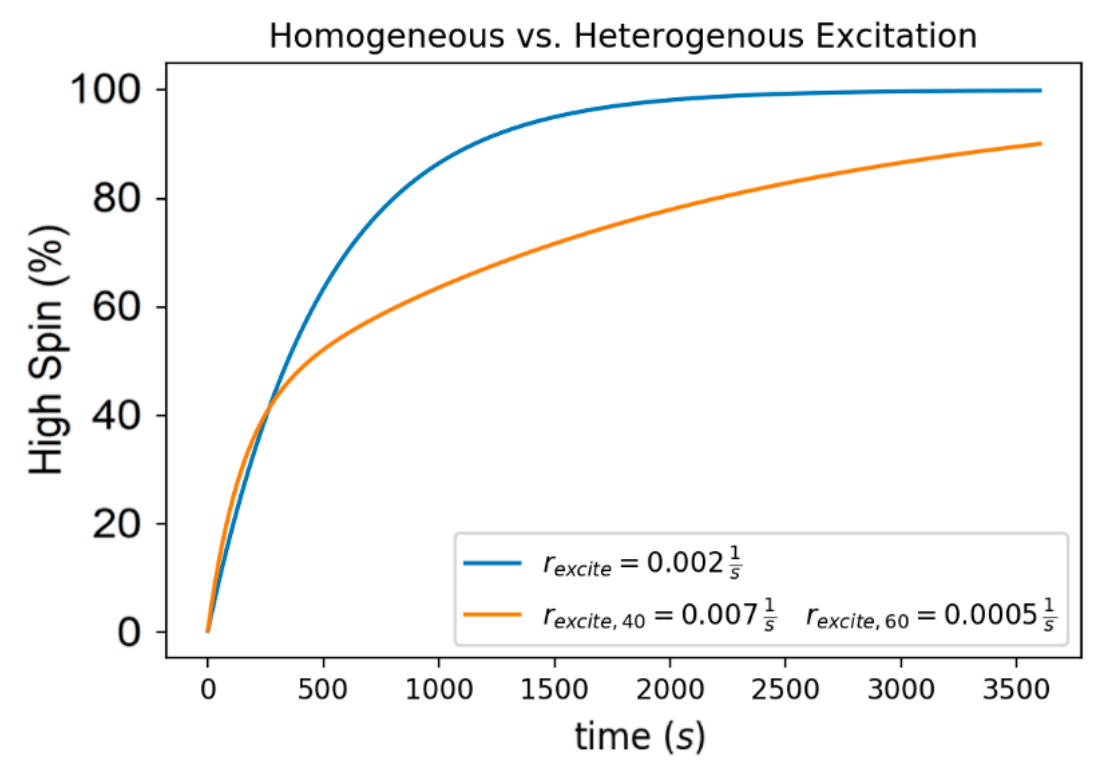

Figure 7. A simulation of the evolution of the high-spin state occupancy in the $\left[\mathrm{Fe}\left\{\mathrm{H}_{2} \mathrm{~B}(\mathrm{pz})_{2}\right\}_{2}(\mathrm{bipy})\right]$ molecular thin film assuming a simple excitation rate uniformly throughout the film (blue) and an inhomogeneous excitation process where $40 \%$ of the film is activated with one constant rate and $60 \%$ of the film at a lower rate that is $10 \%$ of the higher rate (orange).

A single molecule could gain $E=H \cdot \Delta m$ energy for a moment change under the presence of a magnetic field, but with a moment change of $\Delta m=4 \mu_{\mathrm{B}}$ and an applied field $\mathrm{H}=1.8 \mathrm{~T}$, this gain would be $0.42 \mathrm{meV}$ at most. In fact, because of finite temperature effects, leading to moment canting, the actual energy in the vicinity of room temperature would be much smaller. A magnetic-field-dependent change on an energy scale of several $\mathrm{meV}$ is well above that level, and can only be explained by the cooperative coupling of several molecules. This suggests that the spin crossover occurs collectively with a cluster of molecules, consistent with previous work $[21,23]$ which has indicated spin-state domains in $\mathrm{Fe}\left\{\mathrm{H}_{2} \mathrm{~B}(\mathrm{pz})_{2}\right\}_{2}$ (bipy)] thin films.

These activation energy values of 14.5 to $15.9 \mathrm{meV}$ per molecule are close to the 14 to $18 \mathrm{meV}$ value of the thermal activation energy component of the $\mathrm{X}$-ray-fluence-induced transition to the high-spin state for $\left[\mathrm{Fe}\left\{\mathrm{H}_{2} \mathrm{~B}(\mathrm{pz})_{2}\right\}_{2}\right.$ (bipy)] locked in the low-spin state with zwitterion additions [27]. This similarity suggests that the energetics involved in the locking of $\left[\mathrm{Fe}\left\{\mathrm{H}_{2} \mathrm{~B}(\mathrm{pz})_{2}\right\}_{2}\right.$ (bipy)] in the low-spin state by zwitterion additions or by a $\mathrm{NiCo}_{2} \mathrm{O}_{4}(111)$ substrate are comparable. The presence of thermal activation barriers implies that the ligands of $\left[\mathrm{Fe}\left\{\mathrm{H}_{2} \mathrm{~B}(\mathrm{pz})_{2}\right\}_{2}\right.$ (bipy)] are subject to temperature variations. The ligands do contribute to the orbital moment of $\left[\mathrm{Fe}\left\{\mathrm{H}_{2} \mathrm{~B}(\mathrm{pz})_{2}\right\}_{2}\right.$ (bipy)] [12]; thus, thermal effects from the ligands are expected. The significant changes in the relative orbital moment, with temperature as validated by the XMCD measurements, tend to validate the principle that the ligands have dynamical motion enhanced by increasing temperature. As noted above, the spin-to-orbital moment ratio $<\mathrm{S}_{\mathrm{z}}>/<\mathrm{L}_{\mathrm{z}}>$ for $\left[\mathrm{Fe}\left\{\mathrm{H}_{2} \mathrm{~B}(\mathrm{pz})_{2}\right\}_{2}\right.$ (bipy)] thin films on graphite varies widely with small changes in temperature (Figure $4 \mathrm{~b}$ ). For such a wide variation of $\left\langle\mathrm{S}_{\mathrm{z}}\right\rangle /\left\langle\mathrm{L}_{\mathrm{z}}\right\rangle$ to occur, in response to small temperature changes, the ligand contributions to the orbital moment of $\left[\mathrm{Fe}\left\{\mathrm{H}_{2} \mathrm{~B}(\mathrm{pz})_{2}\right\}_{2}\right.$ (bipy)] must be sensitive to temperature. This sensitivity of the orbital moment to the dynamical motion of the ligands, evident in the wide variation in $\left\langle\mathrm{L}_{\mathrm{z}}\right\rangle$ with small changes in temperature, also provides some explanation as to why there is a thermal component of the activation energy barrier in the soft X-ray activation of the spin crossover transition for $\left[\mathrm{Fe}\left\{\mathrm{H}_{2} \mathrm{~B}(\mathrm{pz})_{2}\right\}_{2}(\mathrm{bipy})\right]$ molecular thin films.

Magnetic anisotropy is very characteristic of local moment molecular systems [34]; however, the effect of an anisotropy barrier resulting from the substrate [19,21] or cooperative effects $[21,23]$ cannot be excluded by any data presented here. The fact that 
these ligands are both temperature-sensitive and that there are known cooperative effects $[21,23,25,26]$ indicates that magnetic anisotropy is a very real possibility.

\section{Materials and Methods}

The $\left[\mathrm{Fe}\left\{\mathrm{H}_{2} \mathrm{~B}(\mathrm{pz})_{2}\right\}_{2}\right.$ (bipy)] molecule was synthesized as described elsewhere [20], and characterized as noted elsewhere $[12,19-23,28]$. A schematic diagram of $\left[\mathrm{Fe}\left\{\mathrm{H}_{2} \mathrm{~B}(\mathrm{pz})_{2}\right\}_{2}(\mathrm{bipy})\right]$ is shown in Figure 1. The X-ray absorption spectroscopy measurements of $\left[\mathrm{Fe}\left\{\mathrm{H}_{2} \mathrm{~B}(\mathrm{pz})_{2}\right\}_{2}(\mathrm{bipy})\right]$ thin films were performed at the Advanced Light Source at Lawrence Berkeley National Laboratory on the bending magnet beamline 6.3 .1 at a reduced storage ring current of $15 \mathrm{~mA}$ using circularly polarized, negative helicity photons. Spectra were taken both in the absence of an applied magnetic field as well as in the presence of a 1.8 T applied magnetic field, with the field applied perpendicular to the surface of the film. The incident photon flux was in the region of $10^{11}$ photons $\mathrm{s}^{-1} 0.1 \% \mathrm{BW}^{-1}$. The sample temperature was allowed to equilibrate for $2 \mathrm{~h}$ at each temperature before the measurement, ensuring not only a stable temperature, but also negligible positional drift with respect to the $\sim 80 \mu \mathrm{m}$ diameter of the X-ray beam along the cryostat direction (the X-ray beam spot size is $180 \mu \mathrm{m} \times 80$ at the Advanced Light Source beamline 6.3.1). The total electron yield mode was used to measure the absorption across the Fe $2 p_{3 / 2}\left(L_{3}\right)$ edge, as performed in previous studies [12,19-24] which have also confirmed that the X-ray-induced excitation into the high-spin (HS) state is reversible.

As in previous studies [12], [ $\mathrm{Fe}\left\{\mathrm{H}_{2} \mathrm{~B}(\mathrm{pz})_{2}\right\}_{2}$ (bipy)] was thermally evaporated $[12,19,21-$ $24,28]$ on nickel cobaltate $\left(\mathrm{NiCo}_{2} \mathrm{O}_{4}(111)\right)(\sim 100 \mathrm{~nm})$ thin films grown on $\mathrm{Al}_{2} \mathrm{O}_{3}(0001)$ substrates by pulsed laser deposition (PLD) [12]. The substrate temperature for thermal evaporation was $-33{ }^{\circ} \mathrm{C}$, and the growth rate for $\left[\mathrm{Fe}\left\{\mathrm{H}_{2} \mathrm{~B}(\mathrm{pz})_{2}\right\}_{2}\right.$ (bipy)] molecules was $0.02 \AA$ /s under the high vacuum $\left(1.0 \times 10^{-7}\right.$ Torr). The $\left[\mathrm{Fe}\left\{\mathrm{H}_{2} \mathrm{~B}(\mathrm{pz})_{2}\right\}_{2}\right.$ (bipy)] SCO molecular films were nominally $15 \mathrm{~nm}$ thick; the film thickness was measured with a quartz thickness monitor. After the deposition, the samples were naturally warmed up to room temperature. It has been established [12] that a $\mathrm{NiCo}_{2} \mathrm{O}_{4}$ (111) substrate will lock a 10 to $15 \mathrm{~nm}\left[\mathrm{Fe}\left\{\mathrm{H}_{2} \mathrm{~B}(\mathrm{pz})_{2}\right\}_{2}\right.$ (bipy)] spin crossover molecular thin film largely in the low-spin state, almost independent of temperature. The magnetic properties of the $\mathrm{NiCo}_{2} \mathrm{O}_{4}$ (111) thin films have been studied systematically $[35,36]$. In particular, for the semiconducting $\mathrm{NiCO}_{2} \mathrm{O}_{4}(111)$ films grown on $\mathrm{Al}_{2} \mathrm{O}_{3}$ (001) film, ferrimagnetism occurs below $\mathrm{T}_{\mathrm{C}}=330 \mathrm{~K}$. Although the easy axis is not along the out-of-plane direction, there is significant remanence ( $>50 \%$ saturation value) with a coercivity about 1000 Oe [35]. These experimentally advantageous parameters make $\mathrm{NiCo}_{2} \mathrm{O}_{4}(111)$ very suitable as the substrate for the $\left[\mathrm{Fe}\left\{\mathrm{H}_{2} \mathrm{~B}(\mathrm{pz})_{2}\right\}_{2}\right.$ (bipy)] thin film. Due to the stability of the $\left[\mathrm{Fe}\left\{\mathrm{H}_{2} \mathrm{~B}(\mathrm{pz})_{2}\right\}_{2}(\mathrm{bipy})\right]$ thin film on $\mathrm{NiCo}_{2} \mathrm{O}_{4}$ (111), the experiments can be repeated at several different temperatures.

To enter the high-spin state, a soft $\mathrm{X}$-ray fluence has been seen to be effective, and as noted previously, this is seen for $\left[\mathrm{Fe}\left\{\mathrm{H}_{2} \mathrm{~B}(\mathrm{pz})_{2}\right\}_{2}\right.$ (bipy)] on $\mathrm{NiCo}_{2} \mathrm{O}_{4}(111)$ [12]. The experiments were repeated at different temperatures on a fresh spot of the $\left[\mathrm{Fe}\left\{\mathrm{H}_{2} \mathrm{~B}(\mathrm{pz})_{2}\right\}_{2}\right.$ (bipy)] thin film on $\mathrm{NiCo}_{2} \mathrm{O}_{4}(111)$, to ensure otherwise equivalent starting conditions for each measurement. In addition, control experiments with a swapped order of in-field and field free measurement conditions and various stabilizations time of the electromagnet were made to exclude thermal drift.

Additional X-ray absorption spectroscopy (XAS) and magnetic circular dichroism $(\mathrm{XMCD})$ characterizations of $\left[\mathrm{Fe}\left\{\mathrm{H}_{2} \mathrm{~B}(\mathrm{pz})_{2}\right\}_{2}\right.$ (bipy)] thin films were performed at Advanced Photon Source beamline 4-ID-C at Argonne National Laboratory [37,38]. The spot size was roughly $1 \mathrm{~mm}$ at Advanced Photon Source beamline 4-ID-C. For these XMCD measurements, the samples consisted of nominal $\sim 30 \mathrm{~nm}$ of $\left[\mathrm{Fe}\left\{\mathrm{H}_{2} \mathrm{~B}(\mathrm{pz})_{2}\right\}_{2}\right.$ (bipy)] thin films on HOPG substrates, again prepared using thermal evaporation. The growth rate was calibrated to ensure that the deposition was consistent from sample to sample. These growth rates were then separately checked with a profilometer, as an independent check of film thickness. Graphite, as a substrate, is better suited for studies of magnetic field perturbations of $\left[\mathrm{Fe}\left\{\mathrm{H}_{2} \mathrm{~B}(\mathrm{pz})_{2}\right\}_{2}\right.$ (bipy)] in the high-spin state than $\mathrm{NiCo}_{2} \mathrm{O}_{4}(111)$. Graphite is known as a substrate where $\left[\mathrm{Fe}\left\{\mathrm{H}_{2} \mathrm{~B}(\mathrm{pz})_{2}\right\}_{2}\right.$ (bipy)] undergoes a complete thermal- and 
light-induced spin transition even in the monolayer limit $[25,26]$, very similar to the powder. Substrate effects on the $\left[\mathrm{Fe}\left\{\mathrm{H}_{2} \mathrm{~B}(\mathrm{pz})_{2}\right\}_{2}\right.$ (bipy)] thin film spin state are thus minimal when the substrate is graphite $[25,26]$. Measurements of the Fe $\mathrm{L}_{2,3}$-edge XMCD spectra were taken in total electron yield mode with a $2 \mathrm{~T}$ magnetic field applied nearly perpendicular to the sample surface. In order to eliminate some of the artifacts, the final spectrum was obtained from the difference of two spectra taken at \pm 2 T magnetic field. To study the temperature effects, XMCD data were obtained at several temperatures near room temperature, $\mathrm{T}=\{280 \mathrm{~K}, 290 \mathrm{~K}, 300 \mathrm{~K}\}$.

\section{Conclusions}

There is now clear evidence that a moderate, static magnetic field can affect the soft $X$-ray-induced conversion of $\left[\mathrm{Fe}\left\{\mathrm{H}_{2} \mathrm{~B}(\mathrm{pz})_{2}\right\}_{2}\right.$ (bipy)] thin film spin state, locked in the lowspin state by a $\mathrm{NiCo}_{2} \mathrm{O}_{4}(111)$ substrate. The changes in the activation energy and in the soft X-ray photo-excitation-enhanced spin crossover transition indicate an influence of the magnetic field on the thermal component of the spin-crossover transition. In the presence of a large magnetic field (2T), the ligand contributions to the orbital moment are seen to be sensitive to variations in temperature because the relative orbital moment changes dramatically with small changes in temperature. This is consistent with a temperature dependence of the soft X-ray-induced conversion of the $\left[\mathrm{Fe}\left\{\mathrm{H}_{2} \mathrm{~B}(\mathrm{pz})_{2}\right\}_{2}\right.$ (bipy)] thin film spin state. Deepening the understanding of this relationship between magnetic, electric, and optical factors of the spin-crossover transition is a prerequisite for thermodynamic bases of multiferroic behavior and magneto-electric coupling.

Supplementary Materials: The following are available online at https: / www.mdpi.com/article/ 10.3390 / magnetochemistry7100135/s1. Figure S1 contains X-ray absorption spectra taken at $250 \mathrm{~K}$ with and without the presence of an applied 1.8 T magnetic field. Reference X-ray absorption spectra of the $\left[\mathrm{Fe}\left\{\mathrm{H}_{2} \mathrm{~B}(\mathrm{pz})_{2}\right\}_{2}\right.$ (bipy)] low-spin and high-spin states are shown in Figure S2. The evolution of the high-spin state at $250 \mathrm{~K}$, with and without the presence of an applied $1.8 \mathrm{~T}$ magnetic field, is shown in Figure S3.

Author Contributions: Conceptualization, A.T.N., P.A.D. and R.C; methodology, A.T.N., J.W.F., P.A.D. and R.C; software, A.T.N. and J.W.F.; validation, G.H., A.T.N., A.S.D., P.A.D. and R.C.; formal analysis, G.H., T.K.E., A.S.D., A.T.N., S.Y. and P.A.D.; investigation, G.H., A.T.N., T.K.E., A.S.D., X.J., E.M., C.M., S.Y., J.Z., R.C. and X.X.; resources, X.J., C.M., S.Y., J.Z., R.C. and X.X.; data curation, G.H., A.S.D. and T.K.E.; writing-original draft preparation, G.H., A.T.N. and P.A.D.; writing-review and editing, A.T.N. and P.A.D.; supervision, A.T.N., P.A.D. and R.C.; project administration, A.T.N., P.A.D. and R.C.; funding acquisition, A.T.N., P.A.D. and R.C. All authors have read and agreed to the published version of the manuscript.

Funding: This research was supported by the National Science Foundation through NSF-DMR 2003057 [G. Hao, T. Ekanayaka, Ashley S. Dale, Esha Mishra, Ruihua Cheng, P. A. Dowben] and the EPSCoR RII Track-1: Emergent Quantum Materials and Technologies (EQUATE), Award OIA2044049 [X. Jiang, C. Mellinger, X. Xu]. Use of the Advanced Light Source, Lawrence Berkeley National Laboratory, was supported by the U.S. Department of Energy (DOE) under contract no. DE-AC02-05CH11231, and use of the Advanced Photon Source was supported by DOE's Office of Science under contract DE-AC02-06CH11357. G. Hao was partly supported by an Advanced Light Source Graduate student fellowship throughout this effort.

Institutional Review Board Statement: Not applicable.

Informed Consent Statement: Not applicable.

Data Availability Statement: The data presented in this study arose from the sources cited or are available on request from the corresponding authors.

Conflicts of Interest: The authors declare no conflict of interest. The funders had no role in the design of the study; in the collection, analyses, or interpretation of data; in the writing of the manuscript, or in the decision to publish the results. 


\section{References}

1. Fiebig, M. Revival of the magnetoelectric effect. J. Phys. D Appl. Phys. 2005, 38, R123-R152. [CrossRef]

2. Curie, P. Sur la symétrie dans les phénomènes physiques, symétrie d'un champ électrique et d'un champ magnétique. J. Phys. Théorique Appliquée 1894, 3, 93-415. [CrossRef]

3. Sharma, N.; Bird, J.P.; Binek, C.; Dowben, A.P.; Nikonov, D.E.; Marshall, A. Evolving magneto-electric device technologies. Semicond. Sci. Technol. 2020, 35, 073001. [CrossRef]

4. International Roadmap for Devices and Systems 2020 Edition, Beyond CMOS; 3.4.4 Magnetoelectric Logic; IEEE, 2020; pp. 38-40. Available online: https://irds.ieee.org/editions/2020 (accessed on 5 October 2020).

5. Chikara, S.; Gu, J.; Zhang, X.G.; Cheng, H.P.; Smythe, N.; Singleton, J.; Scott, B.; Krenkel, E.; Eckert, J.; Zapf, V.S. Magnetoelectric behavior via a spin state transition. Nat. Commun. 2019, 10, 4043. [CrossRef] [PubMed]

6. Otsuki, Y.; Kimura, S.; Awaji, S.; Nakano, M. Magnetocapacitance effect and magnetostriction by the field-induced spin-crossover in [MnIII(taa)]. AIP Adv. 2019, 9, 085219. [CrossRef]

7. Jakobsen, V.B.; Chikara, S.; Yu, J.-X.; Dobbelaar, E.; Kelly, C.T.; Ding, X.; Weickert, F.; Trzop, E.; Collet, E.; Cheng, H.-P.; et al. Giant Magnetoelectric Coupling and Magnetic-Field-Induced Permanent Switching in a Spin Crossover Mn(III) Complex. Inorg. Chem. 2021, 60, 6167-6175. [CrossRef]

8. Yum, J.-X.; Chen, D.-T.; Gu, J.; Chen, J.; Jiang, J.; Zhang, L.; Yu, Y.; Zhang, X.-G.; Zapf, V.S.; Cheng, H.-P. Three Jahn-Teller States of Matter in Spin-Crossover System Mn(taa). Phys. Rev. Lett. 2020, 124, 227201. [CrossRef]

9. Zapf, V.S.; Sengupta, P.; Batista, C.D.; Nasreen, F.; Wolff-Fabris, F.; Paduan-Filho, A. Magnetoelectric effects in an organometallic quantum magnet. Phys. Rev. B 2011, 83, 140405. [CrossRef]

10. Kimura, S.; Narumi, Y.; Kindo, K.; Nakano, M.; Matsubayashi, G.-E. Field-induced spin-crossover transition of [MnIII(taa)] studied under pulsed magnetic fields. Phys. Rev. B 2005, 72, 064448. [CrossRef]

11. Bousseksou, A.; Negre, N.; Goiran, M.; Salmon, L.; Tuchagues, J.-P.; Boillot, M.-L.; Boukheddaden, K.; Varret, F. Dynamic triggering of a spin-transition by a pulsed magnetic field. Eur. Phys. J. B 2000, 13, 451-456. [CrossRef]

12. Zhang, X.; N'Diaye, A.T.; Jiang, X.; Zhang, X.; Yin, Y.; Chen, X.; Hong, X.; Xu, X.; Dowben, P.A. Indications of magnetic coupling effects in spin cross-over molecular thin films. Chem. Commun. 2018, 54, 944-947. [CrossRef]

13. Ketsle, G.A.; Levshin, L.V.; Mel'nikov, G.V.; Minaev, B.F. Effect of a magnetic field on delayed fluorescence of anthracene exciplexes. J. Appl. Spectrosc. 1981, 34, 287-291. [CrossRef]

14. Hodges, M.P.P.; Grell, M.; Morley, N.A.; Allwood, D.A. Wide Field Magnetic Luminescence Imaging. Adv. Funct. Mater. 2017, 27, 1606613. [CrossRef]

15. Klein, G.; Voltz, R.; Schott, M. Magnetic field effect on prompt fluorescence in anthracene: Evidence for singlet exciton fission. Chem. Phys. Lett. 1972, 16, 340-344. [CrossRef]

16. Kalinowski, J.; Godlewski, J. Magnetic field effects on recombination radiation in tetracene crystal. Chem. Phys. Lett. 1975, 36, 345-348. [CrossRef]

17. Ern, V.; Merrifield, R.E. Magnetic Field Effect on Triplet Exciton Quenching in Organic Crystals. Phys. Rev. Lett. 1968, 21, 609-611. [CrossRef]

18. Piland, G.B.; Burdett, J.J.; Kurunthu, D.; Bardeen, C.J. Magnetic Field Effects on Singlet Fission and Fluorescence Decay Dynamics in Amorphous Rubrene. J. Phys. Chem. C 2013, 117, 1224-1236. [CrossRef]

19. Zhang, X.; Costa, P.S.; Hooper, J.; Miller, D.P.; N’Diaye, A.T.; Beniwal, S.; Jiang, X.; Yin, Y.; Rosa, P.; Routaboul, L.; et al. Locking and Unlocking the Molecular Spin Crossover Transition. Adv. Mater. 2017, 29. [CrossRef]

20. Zhang, X.; Mu, S.; Chastanet, G.; Daro, N.; Palamarciuc, T.; Rosa, P.; Létard, J.-F.; Liu, J.; Sterbinsky, G.E.; Arena, D.A.; et al. Complexities in the Molecular Spin Crossover Transition. J. Phys. Chem. C 2015, 119, 16293-23302. [CrossRef]

21. Jiang, X.; Hao, G.; Wang, X.; Mosey, A.; Zhang, X.; Yu, L.; Yost, A.J.; Zhang, X.; DiChiara, A.D.; N’Diaye, A.T.; et al. Tunable spin-state bistability in a spin crossover molecular complex. J. Phys. Condens. Matter 2019, 31, 315401. [CrossRef]

22. Warner, B.; Oberg, J.C.; Gill, T.G.; El Hallak, F.; Hirjibehedin, C.F.; Serri, M.; Heutz, S.; Arrio, M.-A.; Sainctavit, P.; Mannini, M.; et al. Temperature- and Light-Induced Spin Crossover Observed by X-ray Spectroscopy on Isolated Fe(II) Complexes on Gold. J. Phys. Chem. Lett. 2013, 4, 1546-1552. [CrossRef]

23. Mosey, A.; Dale, A.S.; Hao, G.; N’Diaye, A.; Dowben, P.A.; Cheng, R. Quantitative Study of the Energy Changes in VoltageControlled Spin Crossover Molecular Thin Films. J. Phys. Chem. Lett. 2020, 11, 8231-8237. [CrossRef] [PubMed]

24. Hao, G.; Mosey, A.; Jiang, X.; Yost, A.J.; Sapkota, K.R.; Wang, G.T.; Zhang, X.; Zhang, J.; N’Diaye, A.T.; Cheng, R.; et al. Nonvolatile voltage controlled molecular spin state switching. Appl. Phys. Lett. 2019, 114, 032901. [CrossRef]

25. Kipgen, L.; Bernien, M.; Nickel, F.; Naggert, H.; Britton, A.J.; Arruda, L.; Schierle, E.; Weschke, E.; Tuczek, F.; Kuch, W. Softx-ray-induced spin-state switching of an adsorbed Fe(II) spin-crossover complex. J. Physics. Condens. Matter 2017, $29,394003$. [CrossRef] [PubMed]

26. Kipgen, L.; Bernien, M.; Ossinger, S.; Nickel, F.; Britton, A.J.; Arruda, L.; Naggert, H.; Luo, C.; Lotze, C.; Ryll, H.; et al. Evolution of cooperativity in the spin transition of an iron(II) complex on a graphite surface. Nat. Commun. 2018, 9, 1-8. [CrossRef] [PubMed]

27. Costa, P.; Hao, G.; N’Diaye, A.T.; Routaboul, L.; Braunstein, P.; Zhang, X.; Zhang, J.; Doudin, B.; Enders, A.; Dowben, P.A. Perturbing the spin crossover transition activation energies in $\mathrm{Fe}(\mathrm{H} 2 \mathrm{~B}(\mathrm{pz}) 2) 2$ (bipy) with zwitterionic additions. J. Physics. Condens. Matter 2018, 30, 305503. [CrossRef] [PubMed] 
28. Palamarciuc, T.; Oberg, J.C.; El Hallak, F.; Hirjibehedin, C.F.; Serri, M.; Heutz, S.; Létard, J.-F.; Rosa, P. Spin crossover materials evaporated under clean high vacuum and ultra-high vacuum conditions: From thin films to single molecules. J. Mater. Chem. 2012, 22, 9690. [CrossRef]

29. Moliner, N.; Salmon, L.; Capes, L.; Muñoz, M.C.; Létard, J.-F.; Bousseksou, A.; Tuchagues, J.-P.; McGarvey, J.J.; Dennis, A.C.; Castro, M.; et al. Thermal and Optical Switching of Molecular Spin States in the $\left\{\left[\mathrm{FeL}\left[\mathrm{H}_{2} \mathrm{~B}(\mathrm{pz})_{2}\right]_{2}\right\}\right.$ Spin-Crossover System $(\mathrm{L}=$ bpy, phen). J. Phys. Chem. B 2002, 106, 4276-4283. [CrossRef]

30. Real, J.A.; Muñoz, M.C.; Faus, J.; Solans, X. Spin Crossover in Novel Dihydrobis(1-pyrazolyl)borate [H2B(pz)2]-Containing Iron(II) Complexes. Synthesis, X-ray Structure, and Magnetic Properties of [FeL $\{\mathrm{H} 2 \mathrm{~B}(\mathrm{pz}) 2\} 2](\mathrm{L}=1,10-\mathrm{Phenanthroline}$ and 2,2'-Bipyridine). Inorg. Chem. 1997, 36, 3008-3013. [CrossRef] [PubMed]

31. Chen, C.T.; Idzerda, Y.U.; Lin, H.-J.; Smith, N.V.; Meigs, G.; Chaban, E.; Ho, G.H.; Pellegrin, E.; Sette, F. Experimental Confirmation of the X-Ray Magnetic Circular Dichroism Sum Rules for Iron and Cobalt. Phys. Rev. Lett. 1995, 75, 152-155. [CrossRef]

32. Zhang, X.; Palamarciuc, T.; Létard, J.-F.; Rosa, P.; Lozada, E.V.; Torres, F.; Rosa, L.G.; Doudin, B.; Dowben, P.A. The spin state of a molecular adsorbate driven by the ferroelectric substrate polarization. Chem. Commun. 2014, 50. [CrossRef] [PubMed]

33. Weber, B. Koordinationschemie Grundlagen und aktuelle Trends; Springer Spectrum, Springer Verlag: Berlin/Heidelberg, Germany, 2014. [CrossRef]

34. Hao, G.; Cheng, R.; Dowben, P.A. The emergence of the local moment molecular spin transistor. J. Phys. Condens. Matter 2020, 32. [CrossRef] [PubMed]

35. Zhen, C.; Zhang, X.; Wei, W.; Guo, W.; Pant, A.; Xu, X.; Shen, J.; Ma, L.; Hou, D. Nanostructural origin of semiconductivity and large magnetoresistance in epitaxial $\mathrm{NiCO}_{2} \mathrm{O}_{4} / \mathrm{Al}_{2} \mathrm{O}_{3}$ thin films. J. Phys. D. Appl. Phys. 2018, 51, 145308. [CrossRef]

36. Mellinger, C.; Waybright, J.; Zhang, X.; Schmidt, C.; Xu, X. Perpendicular magnetic anisotropy in conducting $\mathrm{NiCo}_{2} \mathrm{O}_{4}$ films from spin-lattice coupling. Phys. Rev. B 2020, 101, 014413. [CrossRef]

37. Beamline 4-ID-C. Available online: https:/ / www.aps.anl.gov/Sector-4/4-ID-C/Instrumentation (accessed on 5 October 2020).

38. Shepit, M.; Paidi, V.K.; Roberts, C.A.; Reddy, G.K.; van Lierop, J. Unusual magnetism in $\mathrm{Cu}_{\mathrm{x}} \mathrm{Co}_{3-\mathrm{x}} \mathrm{O}_{4}$ nanoparticles. Phys. Rev. B 2021, 103, 024448. [CrossRef] 